telescope will be to study planetary radiations. Planets not only reflect visible light which they receive from the sun; they absorb and then reradiate considerable quantities of solar energy, largely in the form of the invisible infra-red rays. The special instruments and techniques necessary for the analysis of these radiations are being developed by members of the Institute staff. Much of the information necessary for comparison of conditions on the planets with those on the earth can be obtained only by a more careful and exact study of physical processes taking place on the earth's surface and in its atmosphere. Determinations, to an entirely new order of exactness, of the effect of water vapour, carbon dioxide, ozone and the major atmospheric gases on radiation, are on the programme of research. Incidentally, Dr. Strong pointed out, data obtained in these researches will probably be of very con. siderable value to meteorologists as well as to astronomers.

\title{
EQUATORIAL REGIONS OF THE PACIFIC
}

T his address on June 18 as president of the Pacific Division of the American Association for the Advancement of Science, Dr. H. U. Sverdrup, 'director of the Scripps Institution of Oceanography, stated that the Pacific Ocean is two feet higher on the Australasian side than it is on the American.

As a result of this difference in elevation, there is a narrow, relatively swift current flowing eastward along the equator. If it were not for the friction of water against water, it would move at a rate of about seven knots. Its actual rate is one or two knots. This, however, is as rapid as the current in a great many inland rivers.

The pile-up of water against the Pacific's western shore results from the action of the trade winds. Steady winds blowing across the water from the north-oast in the northern hemisphere's lower latitudes, and corresponding winds from the south-east in the southern hemisphere, keep two great currents moving steadily westward in the tropical Pacific.
Separating them, in the equatorial belt of calms, is the narrow return current, flowing like a river.

This narrow west-to-east equatorial current, however, accounts for only a small part of the water returned across the Pacific. Much larger streams flow away from the equator, to make the return trip at higher latitudes. In the northern hemisphere, the principal returning mass is borne in the Kuroshio or Japan current, which sweeps along the Aleutian chain and turns southward along the North American coast. It is estimated that this current carries more than five thousand times as much water as the Mississippi.

As described by Dr. Sverdrup, the Pacific is a cold monster with a relatively thin, warm skin. Surface temperatures are quite high, reaching as much as $75^{\circ} \mathrm{F}$. But this warm surface layer extends downward only a few hundred feet at most. The great bulk of Pacific ocean water, in the depths, is always cold, most of it only a few degrees above freezing-point.

\section{EXTRACTION OF GOLD FROM SEA-WATER}

$\mathrm{W}$ ITH about five million pounds worth of gold dissolved in each cubic mile of sea-water, man has often sought a way of digging out this treasure. Using electrochemical methods, comparable to those used in electroplating, gold has actually been extracted from the ocean, but unfortunately the cost of the process is five times the value of the gold obtained.

Hopes that this may be reduced to the point where gold may be profitably extracted were raised by Dr. Colin G. Fink, of Columbia University, speaking before the Wilder D. Bancroft Colloid Symposium at Cornell University.

In electroplating, the metal in the plating solution is deposited on the cathode, the negative terminal. But when an effort is made to plate the gold out of sea water in this way the metal precipitates out rapidly, and fails to collect in the solid, crystalline form in which it is desired. By using a rapidly spinning cathode in place of the stationary one, it has been found possible to get a distinctly visible gold deposit. It is the cost of providing the spinning cathode that makes the method impracticable commercially.
In his search for the reason why gold fails to deposit on the stationary cathode, Dr. Fink made the discovery that, when gold passes out of or into solution, two distinct steps are involved. Invisible dissolved gold first goes into myriads of minute particles of colloidal gold, and then later into the crystalline form of the metal. The stationary cathode fails because the metal precipitates out in colloidal form and drops away before crystallizing.

Now a problem remains, namely, conversion of the colloidal gold into the metal crystals. Perhaps it can be accomplished with high-voltage electric currents, or with bombardment of electrons. Dr. Fink intends to try these. "In any event," he said, "it is felt that, on the basis of the discovery, we have advanced one step closer to the commercial recovery of gold from sea water."

Apart from this, however, the discovery is of great theoretical significance, and has practical importance as well. For example, it may hasten development of formulæ for the electroplating of metals such as titanium and vanadium. In this way, it may have far-reaching commercial results whether the gold extraction is accomplished or not. 